\title{
A MULHER E 0 SAGUIM: A RUPTURA DO COTIDIANO NO ENCONTRO COM ANIMAIS EM CLARICE LISPECTOR'
}

\section{THE WOMAN AND THE MARMOSET: THE DISRUPTION OF DAILY LIFE WHEN ENCOUNTERING ANIMALS IN CLARICE LISPECTOR}

\author{
Tânia Sandroni
}

\begin{abstract}
RESUMO: Em vários contos clariceanos, a estrutura básica do enredo se configura com o encontro da protagonista, em geral uma mulher de classe média, com um outro que lhe causa estranhamento. Muitas vezes, trata-se de um animal. Esse encontro inesperado provoca, na personagem, questionamentos em relação à sua vida. Neste trabalho, será apresentada uma leitura do conto "Uma tarde plena", que tem origem em uma crônica publicada na seção "Entre mulheres", produzida pela escritora sob a máscara de Tereza Quadros no jornal Comício em 1952. Pretende-se avaliar como a presença de um saguim no meio de transporte abala, ainda que momentaneamente, a vida domesticada da protagonista; objetiva-se, também, identificar traços da sociedade patriarcal na narrativa e no comportamento da mulher.
\end{abstract}

PALAVRAS-CHAVE: Contos clariceanos. Personagens femininas e animais. Identidade e alteridade em Clarice Lispector.

ABSTRACT: In several of Clarice's short stories, the basic plot structure revolves around the meeting of the protagonist, generally a middle-class woman, with an "other" that provokes a feeling of estrangement. Often, that "other" is an animal. This unexpected meeting makes the character question their life. In this paper, we will present a reading of the short story "Uma tarde plena" ("A plentiful afternoon"), which originates from a text published on the column "Entre mulheres" (Among women), written by the author under the guise of Tereza Quadros for the publication Comício (Rally) in 1952. We intend to evaluate how the presence of a marmoset on the public transport rattles, although momentarily, the protagonist's domesticated life; we also seek to identify traits relating to the patriarchal society in the narrative and in the woman's behaviour.

KEYWORDS: Clarice Lispector's short stories. Female characters and animals. Identity and otherness in Clarice Lispector.

\footnotetext{
${ }^{1}$ Artigo recebido em 30 de agosto de 2021 e aceito para publicação em 20 de outubro de 2021.

${ }^{2}$ Doutora em Teoria Literária e Literatura Comparada pela Universidade de São Paulo (USP). Professora titular da Universidade Paulista. E-mail: taniasandroni@terra.com.br. Link ORCID: https:// orcid.org/0000-0002-9213-6524.
} 


\section{Introduçầo}

Durante muitos anos, Clarice Lispector foi considerada uma escritora alienada das questões sociais e femininas. A crítica dedicou-se, por longo tempo, à avaliação de sua obra sob a perspectiva existencialista ou sob o viés da inovação linguística. Poucas foram as exceções que, no século $X X$, deram ênfase à presença da temática da condição da mulher nos romances e nos contos clariceanos.

A pioneira em revelar na obra da escritora o viés feminino foi Gilda de Mello e Souza no ensaio "O vertiginoso relance", de 1963. A autora apontou, no romance $A$ maçã no escuro, a vocação da minúcia e o apego ao detalhe sensível.

Ligia Chiappini, por sua vez, em um artigo da década de 1990, afirmou que as questões sociais e da mulher eram um ponto cego da crítica sobre a escritora até então. Segundo a autora, a crítica não havia atentado para a presença do feminino como mediação importante para a temática existencial em Clarice Lispector.

Esse aspecto também foi notado por Lúcia Helena, que, no seu livro Nem musa nem medusa, afirmou:

não ler o tema da emergência do feminino em Lispector - indicada com fartura por sintomas até de aparente superfície, como se dá com a galeria de muIheres que ela escolhe para protagonizar seus textos - é não ler Clarice Lispector num de seus traços específicos (HELENA, 1997, p. 27).

Atualmente, nota-se que o olhar da crítica sobre a obra clariceana tem se voltado para a condição da mulher. O número de estudos com base na crítica feminista sobre os romances, os contos e as produções jornalísticas da escritora tem crescido de modo significativo.

Muitas dessas pesquisas têm focalizado a representação da mulher nas narrativas de Clarice Lispector, observando que as questões existenciais que as permeiam são ativadas por condições de gênero e classe. De fato, esses elementos estão presentes desde o início de sua atuação como escritora e como jornalista.

Em 1952, a escritora atuou como colunista feminina sob a máscara de Tereza Quadros, responsável pela página "Entre muIheres" do jornal Comício. O semanário era dirigido por Rubem Braga, Rafael Correa de Oliveira e Joel Silveira. 
A seção feminina era ambivalente em relação à representação da mulher. Ao lado de receitas e dicas de comportamento, comuns na imprensa feminina, havia crônicas com características da escritora e citações de outros autores. Na pesquisa de doutorado, tive a felicidade de identificar a principal fonte para essas citações: o livro $O$ segundo sexo, de Simone de Beauvoir, na época inédito no Brasil.

Assim, ao mesmo tempo em que a colunista reafirmava o estereótipo da mulher burguesa na sociedade patriarcal, também contestava esse mesmo estereótipo com textos questionadores.

Nessa página, Clarice Lispector, como Tereza Quadros, produziu uma crônica que gerou o conto "Uma tarde plena", objeto deste artigo.

\section{0 encontro com o outro}

Uma das características das narrativas clariceanas é a descoberta de si mesmo por meio do encontro com o outro. Nas palavras de Daniela Mercedes Kahn (2005, p. 19), "identidade e alteridade aparecem como dois conceitos inseparáveis na obra de Clarice Lispector, sendo que um se define em função do outro".

Regina Pontieri, na apresentação do livro de Daniela Kahn (2005), afirma que a cena arquetípica da ficção de Clarice Lispector é o enfrentamento entre um 'eu' e seu 'outro'. Essa relação de alteridade, por sua vez, é marcada pela ambivalência, com a "consequente violência do outro" (in KAHN, 2005, p. 11), como acontece, por exemplo, em $A$ hora da estrela.

Ana Carolina Sá Teles (2016), por sua vez, aponta que a relação com o outro na obra clariceana se configura de diversas maneiras, como o espelhamento, a identificação, o estranhamento, a despersonalização do eu ou o aniquilamento do outro.

Na maioria das vezes, a personagem principal é uma muIher de classe média, com sua vida confinada no ambiente doméstico, que sai às ruas, ou seja, ao ambiente público, em uma tarefa cotidiana e é atravessada por um encontro com um ser que Ihe causa estranhamento. Podemos citar, por exemplo, o conto "Amor", de Laços de família, em que um cego mascando chiclete na rua faz com que Ana, a protagonista, saia da rotina e questione seu "destino de mulher". 
Assim, o encontro com o "estranho" provoca, em maior ou menor grau, inquietude, ou seja, desestabiliza a vida até então acomodada em um frágil equilíbrio. É bastante comum que esse outro seja um animal.

Como aponta Evando Nascimento (2012, p. 25),

se há uma categoria que pode ajudar a compreender a questão dos animais (...) em Clarice, essa á a do unheimlich freudiano. Não se trata aqui de psicanalisar as relações entre homens e bichos segundo Clarice, mas de compreender como certo 'estranho familiar' perpassa a visão dessa nossa alteridade (NASCIMENTO, 2012, p. 25).

O não humano, portanto, tem um papel muito importante, pois contribui para que se ultrapassem as barreiras da civilização ocidental.

Maria Ester Maciel aponta a presença da outridade animal na literatura. Segundo ela, os

animais, sob o olhar humano, são signos vivos daquilo que sempre escapa a nossa compreensão. Radicalmente outros, mas também nossos semelhantes, distantes e próximos de nós, eles nos fascinam ao mesmo tempo que nos assombram e desafiam nossa razão (MACIEL, 2016, p. 85).

De fato, nos textos clariceanos, a presença dos animais é uma marca. Galinhas, cavalos, cães, macacos e baratas, por exemplo, são elementos que exercem função fundamental em várias narrativas. Algumas dessas presenças já foram bem enfatizadas pela crítica. Olga de Sá, por exemplo, analisou a figura do cavalo em obras lispectorianas, como no romance de estreia da escritora, Perto do coração selvagem.

Evando Nascimento, por sua vez, destaca a "imensa zoografia ficcional" da escritora. $\mathrm{O}$ autor aponta que sua escrita questiona o saber racional, organizado e antropocêntrico.

Em algumas crônicas, elaboradas para o Jornal do Brasil na década de 1960, Clarice Lispector explicitou sua relação com os bichos, como se vê nos trechos a seguir. 
Às vezes me arrepio toda ao entrar em contato físico com bichos ou com a simples visão deles. Pareço ter certo medo e horror daquele ser vivo que não é humano e que tem os nossos mesmos instintos, embora mais livres e indomáveis. Um animal jamais substitui uma coisa por outra, jamais sublima como nós somos forçados a fazer. E movese, essa coisa viva! Move-se independente, por força mesmo dessa coisa sem nome que é a Vida (LISPECTOR, 199b, p. 332).

(...)

Quem se recusa à visão de um bicho está com medo de si próprio. Mas às vezes me arrepio vendo um bicho. Sim, às vezes sinto o mudo grito ancestral dentro de mim quando estou com eles: parece que não sei mais quem é o animal, se eu ou o bicho, e me confundo toda, fico ao que parece com medo de encarar meus próprios instintos abafados que, diante do bicho, sou obrigada a assumir, exigentes como são, que se há de fazer, pobre de nós (LISPECTOR, 199b, p. 334).

(...)

Não ter nascido bicho parece ser uma de minhas secretas nostalgias. Eles às vezes clamam do longe de muitas gerações e eu não posso responder senão ficando desassossegada. É o chamado (LISPECTOR, 199b, p. 337).

\section{Uma leitura do conto "Uma tarde plena"}

O conto "Uma tarde plena" foi publicado no livro Onde estiveste de noite, de 1974. Ele tem origem em uma crônica, intitulada "Um dia cheio", produzida pela escritora sob a máscara de Tereza Quadros, no jornal Comício, em 1952.

O reaproveitamento de textos é uma constante em Clarice Lispector, o chamado "autoplágio". Neste caso, as mudanças da crônica para o conto são pequenas, pontuais, mas bastante significativas.

Os dois textos mantêm a mesma história: uma mulher, ao entrar no ônibus (ou no bonde), depara com um saguim, que pertence a um passageiro. 


\section{Uma tarde plena}

O saguim é tão pequeno como um rato, e da mesma cor.

A mulher, depois de se sentar no ônibus e de lançar uma tranquila vista de proprietária pelos bancos, engoliu um grito: ao seu lado, na mão de um homem gordo, estava aquilo que parecia um rato inquieto e que na verdade era um vivíssimo saguim. Os primeiros momentos da mulher versus sagüim foram gastos em procurar sentir que não se tratava de um rato disfarçado.

Quando isso foi conseguido, começaram momentos deliciosos e intensos: a observação do bicho. O ônibus inteiro, aliás, não fazia outra coisa.

Mas era privilégio da mulher estar ao lado do personagem principal. De onde estava podia, por exemplo, reparar na minimeza que é uma língua de saguim: um risco de lápis vermelho.

E havia os dentes também: quase que se poderiam contar cerca de milhares de dentes dentro do risco da boca, e cada lasca menor que a outra, e mais branca. O saguim não fechou a boca um instante.

Os olhos eram redondos, hipertireóidicos, combinando com um ligeiro prognatismo - e essa mistura, se lhe dava um ar estranhamente impudico, formava uma cara meio oferecida de menino de rua, desses que estão permanentemente resfriados e que ao mesmo tempo chupam bala e fungam o nariz.

Quando o saguim deu um pulo no colo da senhora, esta conteve um frisson, e o prazer encabulado de quem foi eleita. Mas os passageiros olhavam-na com simpatia, aprovando o acontecimento, $e$, um pouco ruborizada, ela aceitou ser a tímida favorita. Não o acariciou porque não sabia se esse era o gesto a ser feito. E nem o bicho sofria à míngua de carinho. Na verdade o seu dono, o homem gordo, tinha por ele um amor sólido e severo, de pai para filho, de dono para mulher. Era um homem que, sem um sorriso, tinha o chamado coração de ouro. A expressão de seu rosto era até trágica, como se ele tivesse missão. Missão de amar? O saguim era o seu cachorro na vida.

O ônibus, na brisa, como embandeirado, avançava. O saguim começou a comer biscoito. O saguim coçou rapidamente a redonda orelha com a perna fina de trás. $O$ saguim guinchou. Pendurou-se na janela, e espiou o mais depressa que podia - despertando nos ônibus opostos caras que se espantavam e que não tinham tempo de averiguar se 
tinham mesmo visto o que tinham visto. Enquanto isso, perto da senhora, uma outra senhora contou a outra senhora que tinha um gato. Quem tinha posses de amor, contou.

Foi nesse ambiente de família feliz que um caminhão quis passar à frente do ônibus, houve quase encontro fatal, os gritos. Todos saltaram depressa. A senhora, atrasada, com hora marcada, tomou um táxi. Só no táxi lembrou-se de novo do saguim.

E lamentou com um sorriso sem graça que - sendo os dias que correm tão cheios de notícias nos jornais e com tão poucas para ela - tivessem os acontecimentos se distribuído tão mal a ponto de um saguim e um quase desastre sucederem na mesma hora.

"Aposto" - pensou - "que nada mais me acontecerá durante muito tempo, aposto que agora vou entrar no tempo das vacas magras". Que era em geral seu tempo.

Mas nesse mesmo dia aconteceram outras coisas. Todas até que dentro da categoria de bens declaráveis. Só que não eram comunicáveis. Essa mulher era, aliás, um pouco silenciosa para si mesma e não se entendia muito bem consigo própria.

Mas assim é. E jamais se soube de um saguim que tenha deixado de nascer, viver e morrer - só por não se entender ou não ser entendido.

De qualquer modo fora uma tarde embandeirada. (LISPECTOR, 1999a, p. 80-82).

Os trechos sublinhados (por mim) não fazem parte da crônica de 1952, foram acrescentados ao transformá-la em conto. Observa-se que, nesta versão, é enfatizada a associação entre amor e posse. Também se desenvolvem mais traços da personagem. Nota-se que a mulher tem uma vida entediante, pois os acontecimentos do mundo (as notícias) não são para ela, e sua rotina carece de vivências incomuns, a tal ponto que o quase desastre não é visto por ela como algo ruim.

Devemos lembrar que etimologicamente "desastre" significa "má estrela", e, mesmo com a carga semântica negativa, a iminência dele é, de certa forma, "desejada" pela protagonista.

$\mathrm{Na}$ narrativa, acompanhamos o movimento da personagem em relação ao saguim, que passa da repulsa ao afeto. Devemos observar que o saguim não se configura como um animal típico dos cenários urbanos e, assim, sua presença no transporte 
público causa mais estranhamento do que os bichos tradicionalmente domesticados, como o cachorro.

A sucessão de sensações e sentimentos que invade a personagem é expressa por meio dos recursos do narrador onisciente seletivo. Após o susto, aparece a contemplação prazerosa do animal. A personagem repara na fisionomia do bichinho e, na tentativa de classificá-lo como algo familiar, compara-o a um menino de rua resfriado que chupa balas. Essa imagem remete a uma criança que está fora do seu locus adequado e que, ao fazer barulho com a bala e fungar o nariz, chama atenção de uma forma negativa, à primeira vista. O horror da "proprietária", que contemplava com superioridade o que estava fora de seus domínios de classe, aproxima menino de rua e aquele que antes era sentido como um horrendo animal.

A contemplação é interrompida pela ação inesperada do saguim, que pula no colo da mulher. A repugnância provocada pelo primeiro contato físico logo se transforma em simpatia e até em certa afeição, que não chega a ser expressa em gestos, como o de acariciar o animal. Esse novo sentimento é reforçado pela aprovação de todos os passageiros, conquistados pelo bichinho. $O$ animal transforma o espaço impessoal do transporte público em um ambiente de família feliz.

Os gestos do saguim são autênticos, livres. Ele come o biscoito, coça a orelha e espia pela janela. Essas ações são relatadas por meio de períodos curtos, com estrutura sintática paratática, cujo ritmo revela a inquietude do macaquinho. Há algo do encantamento da personagem pela autonomia das ações do animal, que se contrapõem aos comportamentos normatizados das pessoas no transporte público. Em outros termos, a vivacidade do mico contrasta com o comportamento estático dos passageiros.

O olhar do narrador apreende o amor sólido do homem gordo, que tem o saguim como se ele fosse seu cachorro. Note-se que, para construir a explicação do amor entre homem e saguim, o animal é comparado ao cão, já consolidado no imaginário social como animal de estimação extremamente fiel, capaz de construir laços afetivos com os humanos.

No conjunto da narrativa, portanto, o processo de reconhecimento do saguim pela mulher passa por uma gradação de figuras associativas em um movimento de aproximação. No primei- 
ro momento, é um rato; no segundo, um menino de rua ranhento; no terceiro, um cão. Essas imagens não são aleatórias; revelam a transformação dos sentimentos da mulher em relação ao mico.

No final, o narrador onisciente equipara a falta de consciência de si do macaquinho com a da mulher. Ambos vivem sem questionamentos e sem a compreensão de si mesmos. Mulher e saguim apenas existem e se conformam com a vida, que "assim é". A resignação vence, não se vislumbra qualquer possibilidade de alteração do estado das coisas. Mesmo assim, o dia fica marcado como festivo, "embandeirado".

Deve-se enfatizar, ainda, a figura do homem, dono do saguim. Evando Nascimento (2012, p. 23), ao discutir "a tragédia colonizadora" do sujeito masculino sobre todas as "espécies do vivo", afirma que "o apossamento e a dominação que ocorrem no nível da espécie (o Homem $x$ animais e não humanos em geral) repercutem no nível do gênero (masculino x feminino)".

Essa dominação pode ser, como na narrativa, explicada em função do amor, afinal, o homem gordo tem para o bicho um "amor severo", similar ao "de dono para mulher".

Com essa expressão, a escritora aborda explicitamente a condição feminina nas relações conjugais e altera a natureza do amor que o homem sente pelo saguim, destacando o caráter de posse. Na nossa cultura, introjetamos a ideia de que animais de estimação são propriedade de pessoas. Essa associação entre amor e propriedade é ainda reforçada pela frase: "Quem tinha posses de amor, contou".

Assim, a palavra "dono", já aplicada em relação ao animal, foi estendida à mulher. $\mathrm{O}$ vocábulo, escolhido no lugar de "marido", pertence ao universo semântico da propriedade e sugere a submissão da esposa ao homem, afirmada não apenas pela tradição, mas também pela lei. Na segunda metade do século XX, a muIher ainda pertencia ao marido de acordo com a legislação vigente.

Segundo Carla Pinsky, as

próprias leis em vigor no país estabelecem para a esposa um grau muito menor de autonomia. Embora, ao longo do tempo, ocorram algumas mudanças em favor das mulheres casadas, a legislação dessa época não rompe com o modelo de família fundada na assimetria de gênero e geracional. O Código Civil (de 
1916) ainda vigente considera a mulher casada "relativamente incapaz", sem poder de decisão sobre o patrimônio e a prole. Por lei, todo poder se concentra nas mãos do homem, chefe da sociedade conjugal, administrador dos bens e representante legal da família (PINSKY, 2014, p. 210).

Cabe ressaltar que, em outras narrativas da escritora, o dono do animal é também uma figura masculina. É o que se observa na crônica "A conquista difícil de um amor", em que um homem passeia com um quati como se ele fosse um cachorro, transformando sua natureza para "possuir a sua graça". Essa história teve algumas versões e também originou outra crônica, intitulada "Amor, quati, cão, feminino e masculino", publicada em 1971 no Jornal do Brasil.

Em alguns textos, o narrador enfatiza, como no caso de "Uma tarde plena", o peso do homem. A figura do "homem gordo" aparece, por exemplo, em outra crônica de Tereza Quadros, "Hora em que começa o domingo", em que temos o seguinte trecho: "Na frente, um homem gordo, de óculos escuros e boné creme, passava a mão com doçura pelo lombo de uma cachorrinha malhada, sem raça e sem rabo" (in SANDRONI, 2018, p. 136). Nota-se que a cena também remete a uma relação de posse entre homem e bicho, justificada pelo amor. A cronista observa o amor da cachorrinha pelo dono:

Depois, ele entrou na água; a cachorrinha entrou junto. Saiu logo, tremendo de frio, sentou nas patinhas traseiras e ficou tão carinhosa, olhando o homem gordo se embrulhar nas ondas, que dava vontade de ser aquele cidadão, mesmo com as suas banhas, só para possuir um olhar assim suave e carinhoso (in SANDRONI, 2018, p. 136).

O "homem gordo" das narrativas clariceanas surge associado à capacidade de amar, com "um coração de ouro", o que, no entanto, não o impede de possuir e subjugar o outro ser. $A$ desproporção de tamanhos entre o dono e o animal (saguim, cachorrinha) pode sugerir a materialização da dominação, da força. Entretanto, em narrativas clariceanas, pessoas gordas aparecem, muitas vezes, marcadas por certa fragilidade, pela necessidade de 
alguma proteção, como o professor de "Os desastres de Sofia" e a cozinheira de "Por enquanto". No caso dos donos de animais, infere-se que eles necessitam do amor dos seus bichinhos e, para isso, apossam-se deles.

Por fim, cabe apontar que, por meio do narrador onisciente, sabemos que a mulher compara o encontro com o saguim com o quase desastre de trânsito. Além de terem em comum a possibilidade de quebra da monotonia, como já mencionamos, os dois eventos poderiam ter causado alguma transformação mais radical na vida da mulher. Mas essa transformação é interrompida. Ela sai do ônibus, entra em um táxi e segue seu rumo. Só então se lembra do saguim. Os acontecimentos do dia embandeirado ficam registrados como fatos fortuitos na sua vida.

\section{Consideraçôes finais}

O conto "Uma tarde plena", assim como acontece em inúmeras outras narrativas clariceanas, apresenta a quebra de estabilidade na rotina de uma mulher de classe média ao se encontrar com um outro, estranho, no espaço público e revela aspectos do papel feminino na sociedade da época e da relação entre amor e posse.

É comum, na ficção da escritora, que o encontro entre personagem e o outro aconteça quando a mulher está fora de casa, ou seja, deixa o ambiente privado e circula pelo espaço público. No âmbito doméstico, existe um equilíbrio instável, ameaçado, em menor ou maior grau, pelo que vem de fora.

Os elementos que atravessam a rotina das personagens e quebram o habitual apresentam naturezas distintas, mas todos têm em comum a característica de serem estranhos aos olhos da personagem.

Noemi Jaffe (2015) lembra que as palavras "estrangeiro", "extra" e "estranho" têm a mesma origem e remetem ao que está de fora, àquele que não pertence a um grupo. A autora afirma que os contos do livro Legião estrangeira (1964) trazem personagens que se encontram, de algum modo, fora da ordem social, como as crianças, os velhos e os animais.

Como observamos, os animais constituem parte importante da obra de Clarice Lispector na questão da identidade e da alteridade. Ocorre a relação que Daniela Khan (2005), chama de identidade/alteridade figural. 
Evando Nascimento aponta:

O bestiário ficcional clariciano e seus correlatos não destroem o universo humano, mas o relançam no contexto de novas forças históricas, anunciando o advento de outra forma, nem humana, nem anti-humana, mais além. $O$ infamiliar não humano é o que ainda não se conhece de todo, mas que se percebe como parte mais íntima da antiga humanidade (NASCIMENTO, 2012, p. 48).

No caso do conto, a personagem sem nome foi afetada pela presença do saguim no ônibus e, mesmo relutante, entregou-se ao clamor do bicho. Isso alterou, ainda que momentaneamente, a mesmice de sua vida e preencheu de forma prazerosa seu dia, como revela o título "Uma tarde plena".

\section{Referências}

CHIAPPINI, L. Pelas ruas da cidade uma mulher precisa andar. Revista Literatura e Sociedade, USP, n.1, p. 60-80, 1996.

HELENA, L. Nem musa nem medusa. Itinerários da escrita em Clarice Lispector. Rio de Janeiro: EDUFF, 1997.

JAFFE, N. “A legião estrangeira de Clarice Lispector e o efeito de estranhamento". Programa Café Filosófico, 14 de maio de 2015. Disponível em: https://youtu.be/Vy0W7HK9O1U. Acesso em 29 ago. 2021.

KAHN, D. M. A via crucis do outro. Identidade e alteridade em Clarice Lispector. São Paulo: Humanitas/Fapesp, 2005.

LISPECTOR, C. Laços de família. Rio de Janeiro: Rocco, 1998.

LISPECTOR, C. Onde estiveste de noite. Rio de Janeiro: Rocco, 1999a.

LISPECTOR, C. A descoberta do mundo. Rio de Janeiro: Rocco, 1999b.

MACIEL, M. E. Literatura e animalidade. Rio de Janeiro: Civilização Brasileira, 2016.

MELLO e SOUZA, G. Exercícios de leitura. São Paulo: Livraria Duas cidades, 2.ed., 2009. 
NASCIMENTO, E. Clarice Lispector: uma literatura pensante. Rio de Janeiro: Civilização Brasileira, 2012.

PINSKY, C. B. Mulheres nos anos dourados. São Paulo: Contexto, 2014.

SANDRONI, T. A Bela e a Fera: a reafirmação do estereótipo feminino e sua subversão nas colunas de Tereza Quadros, máscara de Clarice Lispector. Tese. Departamento de Teoria Literária e Literatura Comparada da Faculdade de Filosofia, Letras e Ciências Humanas da Universidade de São Paulo, 2018.

TELES, A. C. S. A relação entre pessoas e animais em contos de "A legião estrangeira", de Clarice Lispector. Opiniães, [S. I.], v. 4, n. 6-7, p. 207-220, 2016. Disponível em: https://www.revistas.usp.br/opiniaes/article/view/115199. Acesso em: 19 set. 2021. 